ORIGINAL RESEARCH ARTICLE

\title{
Gender-Based Violence among Married Women in Debre Tabor Town, Northwest Ethiopia: A Qualitative Study
}

DOI: 10.29063/ajrh2017/v21i4.11

\author{
Achenef A. Muche ${ }^{1,2 *}$, Adeyemi O. Adekunle ${ }^{3}$, Ayodele O. Arowojolu ${ }^{3}$
}

Pan African University Life and Earth Science Institute (PAULESI), University of Ibadan, Ibadan, Nigeria ${ }^{1}$, Department of Epidemiology and Biostatistics, Institute of Public Health, University of Gondar, Gondar, Ethiopia ${ }^{2}$, Department of Obstetrics and Gynecology, University College Hospital, University of Ibadan, Ibadan, Nigeria ${ }^{3}$

*For Correspondence: Email: ashua2014@gmail.com; Phone: +2349066989860

\begin{abstract}
Gender-based violence is one of the major public health problems in Ethiopia. This study aimed to assess the perception and attitude of the community towards gender-based violence among married women in Northwest Ethiopia. A qualitative study was conducted using the purposive sampling technique for the three focus group discussions and ten in-depth interviews among married women. Data was analyzed thematically using version 3.4 of the Open Code Software. Most of the participants perceived that gender-based violence was acceptable in the community, violent acts needed to be considerably tolerated rather than condemned. Additionally, participants perceived that the consequences of gender-based violence were mild, and its elimination was difficult. Domestic violence was found to be common, marital rape was not clearly understood, and there was no tendency to disapprove it. This study revealed that the attitude of people and traditional norms played the major role in determining the acceptability of gender-based violence on married women. Increasing awareness on the consequences of gender-based violence, strengthening of women empowerment, involving different stakeholders on the provision of education, amending and enforcing the existing laws, and providing professional help to stop or reduce violence against women are recommended. (Afr J Reprod Health 2017; 21[4]: 102-109).
\end{abstract}

Keywords: Gender-based violence, attitude, cultural norms, domestic violence, sexual coercion, rape

\section{Résumé}

La violence basée sur les sexes est l'un des problèmes majeurs de santé publique en Ethiopie. Cette étude visait à évaluer la perception et l'attitude de la communauté envers la violence sexiste chez les femmes mariées dans le nord-ouest de l'Éthiopie. Une étude qualitative a été menée en utilisant la technique d'échantillonnage raisonnée pour les trois groupes de discussion et dix entretiens approfondis entre femmes mariées. Les données ont été analysées thématiquement en utilisant la version 3.4 du logiciel Open Code. La plupart des participants ont estimé que la violence sexiste était acceptable dans la communauté, que les actes violents devaient être considérablement tolérés plutôt que condamnés. De plus, les participants ont perçu que les conséquences de la violence sexiste étaient légères et que son élimination était difficile. La violence domestique était courante, le viol conjugal n'était pas clairement compris et il n'y avait aucune tendance à le désapprouver. Cette étude a révélé que l'attitude des gens et les normes traditionnelles jouent un rôle majeur dans la détermination de l'acceptabilité de la violence sexiste sur les femmes mariées. Une sensibilisation accrue aux conséquences de la violence sexiste, le renforcement de l'autonomisation des femmes, l'implication des différentes parties prenantes dans l'éducation, l'amendement et l'application des lois existantes et une aide professionnelle pour arrêter ou réduire la violence contre les femmes sont recommandées. (Afr J Reprod Health 2017; 21 [4]:102109).

Mots-clés: Violence basée sur le genre, attitude, normes culturelles, violence domestique, coercition sexuelle, viol

\section{Introduction}

Gender-based violence (GBV) is one of the most widespread human rights abuse that endangers the physical integrity and the emotional well-being of victims, particularly women and girls across the 
world $^{1}$. It is the centerpiece for hindrance of the efforts for the promotion of women's health, gender equity, and empowerment ${ }^{2}$.

According to the United Nations, genderbased violence is any violent act that is perpetrated based on socially ascribed gender differences ${ }^{3}$. This umbrella term encompasses those types of intimate partner violence (IPV) and non-partner rape, as well as a range of violent acts including physical, psychological, economical, sexual, exploitive or coercive acts, and harmful traditional practices ${ }^{3}$.

Although most studies charge men with perpetuation of domestic violence, there is lack of evidence affirming that male victims of the threat also exist ${ }^{4}$. Violence by intimate partners has been identified as a major cause of injury to women ${ }^{4}$. Different studies demonstrate that physical and sexual abuse of women has resulted in a wide range of negative health outcomes, such as gynecological disorders, HIV/AIDS, unwanted pregnancy, abortion, still birth, gastrointestinal disorders, chronic pain syndromes, and mental health disorders ${ }^{4-7}$. A study conducted among rape victims attending a hospital in Adigrat town, Ethiopia, found that physical and genital injuries, sexual and psychiatric problems were the common consequences of rape ${ }^{8}$. While there is a considerable debate about the causes of violence against women, it is now universally accepted that there are a range of risk factors, such as poverty, alcohol, and drug use. The primary underlying factors which facilitate such abuse are beliefs about gender and the respective roles of men and women in society and in family life ${ }^{9,10}$.

Gender- based violence estimates show that currently, between $8-70 \%$ of women are assaulted physically and sexually by their male partners at least once in their life time worldwide? ${ }^{9}$ In accordance with Zambia Demography and Health Survey (ZDHS) data, 27\% of married women were beaten by their partners, and about $13 \%$ of the $15-19$ years old were sexually coerced ${ }^{11}$. A hospital-based study in Nairobi reported a $61.5 \%$ prevalence of sexual violence and a $38.5 \%$ prevalence of physical abuse. The majority (72.3\%), of the victims of the gender-based violence were married, and alcohol consumption was a significant contributor in $10.1 \%$ of the cases ${ }^{12}$. A study conducted in South East, Nigeria, showed that $58.9 \%$ of women faced attacks during pregnancy, and $21.3 \%$ had forced sexual intercourse $^{13}$. Reports from the WHO show that most victims of gender-based violence are unable to reveal the violence they face due to stigma, shame, or other social and cultural factors ${ }^{14,15}$.

In Ethiopia, more than two-thirds (68\%) of married women reported some form of physical or sexual violence by their husbands/partners. Although the figure $(68 \%)$ indicated a drop from what it was observed in $2004(81 \%)$, violence was still highly prevalent ${ }^{16,17}$. Studies conducted in different parts of Ethiopia report such high prevalence of gender- based violence as $45 \%$, $76.5 \%, 64.7 \%, 31 \%$ and $50.8 \%$ for South, West, Southwest, North, and Northwest of the country respectively ${ }^{18-22}$.

Some cross-sectional studies have been done in Ethiopia on the prevalence, risk factors, and health outcomes of gender-based violence among women ${ }^{18-22}$. However, the views of the communities on gender-based violence are not well explored in Ethiopia in general, and in the study area. Thus, this study is aimed to explore the community's perception and attitude towards gender-based violence among married women in Debre Tabor town, Northwest Ethiopia.

\section{Methods}

A qualitative study was conducted from May to June 2015 in Debre Tabor town, Northwest Ethiopia. The town is located $99 \mathrm{~km}$ from Bahir Dar and $667 \mathrm{~km}$ from Addis Ababa, Ethiopia. According to the Central Statistical Agency (CSA), the population of Debre Tabor town was estimated at about 78,703 $(\text { Male }=37,682 \text {, Female }=41,021)^{17}$.

A total of three focus group discussions and ten in-depth interviews were conducted with the participants who were selected purposively. For the focus group discussions, the participants were married victims of gender-based violence, female family arbitrators (including opinion leaders and religious figures representing the major religions in the community), and professionals (health professionals and gender officers who were married women) who had closer insight about gender-based violence, were included in the study. The in-depth interviews were conducted with ten women who were victims of violence, families of victims, and law enforcement bodies (a judge and a police officer) involved in resolving domestic matters. The number of the in-depth interview participants were determined by saturation of ideas.

Open-ended unstructured and flexible discussion guide was prepared to collect data. The 
Table 1: Socio-demographic Characteristics of Participants, Debre Tabor Town, May to June 2015 $(\mathrm{n}=30)$

\begin{tabular}{ll}
\hline Characteristics & Number (\%) \\
\hline Types of marriage & \\
Monogamy & $28(93.3)$ \\
Polygamy & $2(6.67)$ \\
Religion & \\
Christians & $26(86.7)$ \\
Muslims & $4(13.3)$ \\
Previous place of residences & \\
Urban & $21(70)$ \\
Rural & $9(30)$ \\
Educational status & \\
No formal education & $8(26.7)$ \\
Primary education & $10(33.3)$ \\
Secondary education & $6(20)$ \\
Higher education & $6(20)$ \\
Employment status & \\
Unemployed & $17(56.7)$ \\
Employed & $13(43.3)$ \\
\hline
\end{tabular}

discussion guide to identify factors involved in the occurrences of gender-based violence was prepared based on the ecological model of understanding intimate partner violence against women ${ }^{23}$. During the data collection and initial analysis preunderstanding was put within brackets ${ }^{24}$. In-depth interview guides were informed by the preliminary results of the FGDs and were tailored to the types of participants. Issues in the guides tried to address women's perception and attitude towards genderbased violence experiences, the meanings they give to acts of violence, the reason and its impact on reproductive health outcomes.

Two trained female nurse research assistants were recruited to facilitate the focus group discussions. The principal investigator was responsible for conducting the in-depth interviews and moderating the FGDs. Participatory techniques, like free-listing, ranking, and diagrams of violent acts were used to enrich the focus group discussions. Both FGDs and in-depth interviews were taperecorded, and notes were taken simultaneously. A diary of the field experiences and reflections was also kept. The FGD took 60 to 90 minutes, whereas the in-depth interview lasted about 60 minutes.

The interview was conducted using study participants' local language "Amharic". Audiotaped data and the detailed notes were transcribed and translated into English. The interview transcripts were coded and fed into the version 3.4 of the open code software and analyzed thematically.
The participants of the interview and the focus group discussions were informed of all aspects of the study, including purpose, risk, benefits, and all safety measures to be taken. They were also informed that none of their personal information would be recorded. Services received from partner agencies would not be affected by participation in or refusal to participate in the study and, they were assured of the confidentiality of their responses, considering the guidelines on ethical and safety recommendations for research on domestic violence against women ${ }^{25}$.

Ethical clearance was obtained first from getting approval from the Department of Obstetrics and Gynaecology, University of Ibadan and Pan African University Institute of Life and Earth Sciences (PAULESI). The request letter for data collection was submitted to South Gondar Zone Health Department (SGZHD); in turn they sent the letter to pertinent bodies to get approval for data collection. Verbal consent was obtained from the participants after explaining the purpose of the study. To ensure confidentiality, their names and other personal identifiers were not registered in the format. It was explained to the participants that they had the right not to respond to questions if they were not comfortable during the interview. Finally, the questionnaire and the tape records were kept secure after data entry was completed.

\section{Results}

Three focus group discussions and ten in-depth interviews involving a total of thirty participants were carried out. The median age of the study participants was 35 (range: 18-72 years). The details of socio-demographic characteristic are shown in Table 1.

\section{Experience of gender-based violence}

Almost half of the participants said that genderbased violence was very common and happened in school environments, streets, during transportation, in offices, at home, and even in religious organizations. Sexual violence, especially verbal harassments and unwanted intentional body contacts with women are considered as part of social life. Indeed, in the FGDs, all of the participants believed that almost all women experienced violence in the rural area. They said many different forms of violence were experienced by women in both urban 
and rural settings. The in-depth interview participants stated that physical violence, sexual violence, emotional abuse and coercive control were all frequently experienced either by themselves or by other members of the community.

A 48-year-old woman explains that “... gender-based violence among married women is common. It is not only what we hear but what we are experiencing in our day- to- day life. For example, there is a guy living near our home; he always forces his wife to do something against her interest and beats her and threatens her family in case she refuses to do..." (FGDA4).

Some of the FGD and most of the in-depth interview participants said that in Ethiopia, genderbased violence within marriage was not considered a crime, thus suggesting that gender-based violence between husband and wife was considered as a private matter and indicated the presence of love between partners. This situation posed great risks for married women.

A 35-year-old married woman (police officer) said " ...always fights are expected between a man and a woman who have been in relation or in union, even family arbitrators cannot stop it because it is culturally acceptable..." (IDI1).

Most participants agreed that a woman must satisfy the sexual desire of her husband even though she is not happy in her relationship. A 30-year-old woman says "My husband needs too much sex; he is also older, more experienced than me and he knows all sorts of sex acts. He is demanding much sex than I could cope with; it is a tormenting experience. Earlier I have informed my uncle about my situation, and he has discussed the issue with my husband. His answer is; the reason I have chosen a young girl is to get satisfaction from her. I have informed my uncle that I am being sexually abused. Then I divorced because it was beyond what I could bear...." (IDI6).

Most participants have explained that beating a wife is not a problem. It is culturally acceptable. A 31-year-old woman reports "My husband perceives that I am born to serve him all the time. He is the head of the household. He is the decision maker for everything in the household. I frequently slept without eating food if he did not come back home. If I ask any "why" question, he immediately beats me. When I tell my friends and family, the punishment is double." (IDI4).

\section{Marital rape}

Most participants believe that there is no marital rape. A husband cannot rape his wife because rape happens to unmarried women only or to single ladies. He has the right to do any type of sex as well, accept his sexual desires at any time. She has no right to say no to sex. On the other hand, a few participants believe that anything done against the interest of a woman is violence. Therefore, having forced sex with a woman is unacceptable. They state that anything that has a component of force is wrong. A woman who refuses to have sexual intercourse for any reason is coerced by the man who cares little about her feelings. Coerced sex was perceived as another dimension of male dominance.

Besides, a 45-year-old woman explains that "Most people cannot differentiate between rape and normal sex. If they do, they see it as their fault. That is why some people keep it to themselves. Every husband cannot rape his wife; he is doing normal sex. Even the Bible says a husband can do anything with his wife..." (FGDB3).

Few of the participants from the FGDs did not like to talk about forced sex in marriage. They said that the word was inappropriate to the context. The following quotations illustrate this sentiment. "If you call sex with a husband a rape, what would you call the illegal forced sex occurring outside marriage?" (FGDC7). On the other hand, few participants agreed about the presence of marital rape which they defined as any sexual activity without the woman's consent.

A 33-year-old woman (judge interviewee) says "the family law rules out the existence of marital rape. Marital partners have a legal obligation to make love to each other' (IDI5).

Similarly, a 28-year-old woman arbitrator participant says "My husband must treat me very well in any situation. He must always care for me. He must understand my feelings. He must understand my sexual interest. If I do not want to have sex now; this is my right. If he makes love 
without my permission, this is marital rape! So, there is marital rape in our community" (IDI5).

\section{Sexual coercion}

Most of the participants believe that domestic violence and sexual coercion happens everywhere. Mainly, it is experienced among family members with their housemaid, and sometimes it is happened with step fathers especially partners lived in separated place than partners lived together in the same place.

A 33-year-old woman says that "girls living with their step-fathers are more likely to experience sexual violence. I know a girl living with her mother and step-father. Her step-father forces her to have sex with him when her mother goes to work." (FGDB2).

A 39 years old participant also says "I have been a servant for more than 10 years. A mother in the home is too busy. She is always busy trying to improve the life of her family, but her husband spends most of his time drinking alcohol and chewing "Khat". Since she gets tired, she cannot have sex at night. Then, once upon a time he asked me for sex. I agreed immediately. Since, this day I have sex with him and he started ignoring his wife frequently. He asked to marry me after separating from his wife. He said he was happy with my sexual partnership. We continued with our secret relationship for more than three years. Finally, he divorced his wife and married me. One of his younger sons also asked me for sex. After some days I did it with him. I felt ashamed and depressed. I never told anyone, but I had sex with both!' (IDI8).

\section{Reasons of gender-based violence}

Almost all participants said that gender-based violence was a deep-rooted problem in the community because culture accepts male dominance. As a result, females have been undermined and remain to exhibit permissive attitude towards violent acts. Throughout the focus group discussions, participants kept on referring to the violence that takes place when women get married or have boyfriends. The violence, they argue, denies women the pleasure they expect from getting married or having boyfriends. Most women perceived relationships with men as ways out of poverty, so they feel they must tolerate and accept any violence from sexual partners. Additionally, gender-based violence occurred due to a woman entering in to a relationship with little attention paid to the behavior of the man.

A 27- year old woman explains that “...Poor perception of the community towards the female has a great contribution to the occurrence of genderbased violence. It is believed that ladies are not wise and have to be beaten to make them do the right things. Women have to be beaten, which results in poor confidence and low self-esteem. In addition, since our culture favors male dominance, to show their power, dominant men usually beat women to keep their esteem in the community (FGDC7).

A 20- year old woman (previously commercial sex worker) also says "... The reason for violent acts against women is exposed dressing and spending their time in unsafe places. I was a commercial sex worker for 6 years. Because of my naked dressing style, I attracted many young men to the bar and night club. I am doing this for monetary gain only, but I faced challenges to satisfy their sexual desire. After sex, most of them beat me..." (IDI3).

Few participants explained that women's poor ability in decision making and considering violence as an expression of love are major reasons for acts of gender-based violence. A 34-year-old woman says "...God does not allow me to decide everything in my house; only my husband has the power to decide. He can even beat me! Beating shows how much he loves me. If I decide, it means I do not respect him! ..." (IDI10).

The participants also mentioned different reasons, including lack of knowledge as causes of gender-based violence among men. Low educational status of women, watching pornographic films, alcohol intake and drug addiction which intoxicate men also encourage violence.

A 27-year-old woman says “...Genderbased violence is because of poor educational status of women; if they are not educated, they are bound to be in the hands of men; they are dependent..." (IDI4).

A 22-year-old woman also says " “...My husband has loved me ever since my childhood. We grew up together. I believe life without him is difficult. He also says life without me is too difficult. After long relationship, we married and started to enjoy life, and we got one child. Recently my husband started watching pornography. During 
sexual intercourse, he asks me to do like what he saw in pornographic films. He also needs oral sex and anal sex. He wants me to use different sex positions; I cannot cope with all. As a result, he started to spat and beat me..." (IDI9).

\section{Consequences of gender-based violence}

Fistula, disability, HIV/AIDS, unwanted pregnancy, abortion and still birth are among many of the consequences of gender-based violence. A 24- year old woman says "...We were married for five years. He always beats me. During my first pregnancy, exactly at 2 months, he beat me, and I had miscarriage. I became pregnant for the second time. But then he continued beating me again and I had another miscarriage. Still, I tried, and I was pregnant for the third time. But to my dismay, the fetus was aborted. Finally, we divorced, and I faced secondary infertility "(IDI5).

A 28-year-old woman explains "....Most women came to get abortion care services in our health center. The reason for unwanted pregnancy is sexual violence by employers and/or partners. However, sexually abused females do not tell the legal body due to fear of the perpetrators "(FGDC4).

\section{Discussion}

While few participants had some differences in what counted as an act of spousal violence, the understanding was broad and subjective as characterized by doing undesirable things on one's partner, against the interest of and/or without the consent of the person. Most participants provided a more formal definition of gender-based violence encompassing physical, sexual, psychological and economic dimensions and different cultural issues. Beating and verbal aggression were mentioned by almost all as expressions of partner violence.

A dominating theme emerging from this research is the high level of gender-based violence, particularly among married women which is generalized within the communities. This is supported by a research finding among displaced women in Colombia. The finding demonstrates a substantial level of violence against women, including non-consensual sex, physical violence by someone other than a current husband/partner, and a lifetime intimate partner violence, such as physical and/or sexual violence ${ }^{27}$.
Almost all participants felt conflicts are common among married partners. They say disagreements are expected in marriage when two people with differing thoughts and backgrounds are in union. Moreover, the interaction existing between any two people as husband and wife is filled with emotions and there are times when emotions could override resulting in conflicts. The demographic and health survey of Ethiopia also indicates that most women believe a husband is justified in beating his wife at least for one reason ${ }^{17}$.

Most of the participants agree that there is no marital rape. Rape only happens on unmarried women or on single ladies. A husband cannot rape his wife as he has the right to do any type of sex act with her. Thus, she must accept his request for sex at any time. She has no right to say no. A cultural perspective mentioned to condone forced sex was that women do not express their sexual desire openly, and men would have to take the initiative, leaving matters of sex to their discretion ${ }^{19}$.

This study revealed the greatest ambivalence around marital rape. Most people believe that once couples are in marriage rape is irrelevant. While men were more likely to legitimize sex without consent in marital union, women were also reluctant to recognize it as rape or an act of violence for that matter ${ }^{27}$. On the other hand, many other participants believed that anything done against the interest of a woman was violence; therefore, having forced sex with a woman was unacceptable. They indicated that anything that has a component of force was wrong. It was said that women refuse sex for some reasons, and a man who coerces his wife is one who does not care about her feelings. Coerced sex was perceived as another dimension of male dominance. This was substantiated by referring to the undesirable consequences of forced sex, like unwanted pregnancy $^{28}$.

Domestic violence is a common problem and married women suffer from such acts. The severity of domestic violence is high due to failure on the part of victims to expose their problems, because of cultural taboos, monetary gain or business given by perpetrators, or fear of perpetrators. This is consistent with other research findings in Ethiopia which demonstrate that domestic violence is a common problem in the family, but victims cannot explain the situation about the abuse ${ }^{19,22}$. 
As explained by victim participants, most of the reasons for committing violent acts include partners feeling offended and/or hurt, self-defense during marital conflict, substance abuse, excessive alcohol consumption, "khat" chewing, drug intake, male dominance and women's poor decision making in the household. This is supported by different studies conducted in Ethiopia ${ }^{21,22,28}$. Moreover, other studies explained that perceived male dominancy and female inferiority are the predominant factors that promote practices of gender-based violence, ${ }^{9,31}$. The results of this study also showed that many women are abused following excessive alcohol consumption by their partners. This corroborates the already established link between alcohol and violence. Different studies have documented that many men who abuse alcohol have been violent to female partners and are perpetrators of domestic violence $^{30,32}$.

Almost all the participants explained that gender-based violence increases the risk of different adverse reproductive outcomes, such as unwanted pregnancy, abortion, miscarriage, still birth, HIV/AIDS and fistula among married women. This finding is consistent with a study conducted in India, where women who were victims of genderbased violence experienced increased risks of multiple forced terminations of pregnancies ${ }^{30}$. The association between gender-based violence and adverse reproductive health outcomes might be that women who are physically and sexually violated have limited access to contraception which leads to unwanted pregnancies and usually ends up in abortion. Violence during pregnancy also results in loss of the pregnancy in the form of miscarriage or still birth, especially if there is a physical attack during pregnancy which traumatizes the baby in utero.

Most participants advised that concerned bodies like police officers, experts in women's affairs, prosecutors and judges should be equipped with appropriate knowledge and skills necessary to handle gender-based violence. In addition, there should be a legal protection for victims of genderbased violence so that the offender does not attack again or take any form of revenge. Most of the participants suggested that the court should establish a special center that works on gender-based violence and emphasizes the empowering of women. Female empowerment through education, economic independence, respect for women's rights, and political representation was also cited as the second most viable solution. This makes sense, as empowered women are believed to be less liable to and less tolerant of an abusive partner.

\section{Conclusion and Recommendations}

In the study community, the attitude of the people and traditional norms influence the acceptability of the act of gender-based violence against women. Most victims tolerate the incident, while a few defend themselves from violent partners. The suggested measures for stopping or reducing violence focused on the empowerment of women and the provision of education for raising awareness using a variety of approaches targeting different stakeholders at all levels. It is recommended that more efforts are needed to dispel myths, misconceptions and traditional norms and beliefs about gender-based violence in the community. There is a need for amending and enforcing the existing laws as well as formulating new laws concerning violence including marital rape. Moreover, providing professional help at all levels is essential. There is an insufficient understanding of violence against women in its contemporary use, and many people hold a non-disapproving stance regarding violence against women by their spouses, this calls for a culturally sensitive information, education and communication intervention.

\section{Contribution of Authors}

AAM conceptualized the research problem, preparing the proposal, designed and conducted the study, statistical analysis, interpretation of the findings and preparing of the manuscript. AOA and AOA revised the proposal and participated in manuscript writing. All authors read and approved the final manuscript.

\section{Competing Interests}

The authors declare that they have no competing interests.

\section{Acknowledgements}

We are grateful to Pan African University and Africa Union Commission for funding this study. We thank the research assistants and study participants. 


\section{References}

1. World Health Organization (WHO), WHO multi-country study on women's health and domestic violence against women. Geneva, Switzerland, 2005.

2. Yemane B. Multi-country Study on Women's Health and Domestic Violence against Women, sponsored by the World Health Organization. Switzerland, 2003:1-28

3. United Nations General Assembly: Declaration on the Elimination of Violence against Women. Edited by United Nations. Geneva: A/RES/48/104; 1993.

4. Ellsberg M, Jansen H, Heise L, Watts CH and GarciaMoreno C. Intimate partner violence and women's physical and mental health in the WHO multi-country study on women's health and domestic violence: An observational study. The Lancet. 2008; 371: 11651172.

5. Loxton D, Schofield M and Hussein R. Psychological health in midlife among women who have ever lived with a violent partner or spouse. Journal of Interpersonal Violence. 2006; 21: 1092-107.

6. Plichta SB and Falik M. Prevalence of violence and its implications for women's health. Women's Health Issues. 2001; 11: 244-58.

7. Romito P, Turan JM and De Marchi M. The impact of current and past interpersonal violence on women's mental health. Social science \& medicine. 2005; 60(8):1717-27.

8. Gessessew A and Mesfin M. Rape and related health problems in Adigrat Zonal Hospital, Tigray Region, Ethiopia. Ethiopian Journal of Health Development. 2004, 18 (3): 140-144.

9. Heise L, Elesberg M and Gottemoeller M. Ending Violence Against Women. Population Report. 1999; 11:1-43.

10. Fals-Stewart W. The Occurrence of Partner Physical Aggression on Days of alcohol Consumption: A Longitudinal Diary Study. Journal of Consulting and Clinical Psychology. 2003; 71: 41-52.

11. Central Statistical Office (CSO), Zambia Demographic and Health Survey 2001/2002. Calverton, Maryland, USA: Central Board of Health, and ORC Macro. 2003.

12. Saidi H, Awori KO and Odula P. Gender-associated violence at a woman's hospital in Nairobi. East African Medical Journal, 2008; 85 (7):347-354.

13. Okemgbo CN, Omideyi AK and Odimegwu CO. Prevalence, patterns and correlates of domestic violence in selected Igbo communities of Imo State, Nigeria. African journal of reproductive health. 2002; 6 (2): 101-14.

14. World Health Organization (WHO), WHO multi-country study on women's health and domestic violence against women. Summary report of initial results on prevalence, health outcomes and women's responses. Geneva, 2005.

15. Krug E, Dahlberg L and Mercy J. World Report on Violence and Health. WHO, Geneva, Switzerland, 2002: 372 .

16. Central Statistical Agency (CSA): Ethiopia Demographic and Health Survey 2005. ORC Macro, Calverton, Maryland, USA. 2006; 235-251

17. Central Statistical Agency (CSA), Ethiopia Demographic and Health Survey 2010. ORC Macro, Calverton, Maryland, USA. 2011; 60-68

18. Deyessa N, Kassaye M, Demeke B and Taffa N: Magnitude, type and outcomes of physical violence against married women in Butajira, South Ethiopia. Ethiop Medical Journal. 1998; 36 (2):83-92.

19. Abeya $G$, Afework $F$ and Yalew W. Intimate partner violence against women in Western Ethiopia: prevalence, patterns and associated factors. BMC Public Health. 2011; 11 (913):1-18.

20. Deribe K, Beyene BK, Tolla A, Memiah P, Biadgilign S and Amberbir A. Magnitude and correlates of intimate partner violence against women and its outcome in Southwest Ethiopia. PloS one. 2012; 7(4):e36189.

21. Feseha G, G/mariam A and Gerbaba M. Intimate partner physical violence among women in Shimelba refugee camp, Northern Ethiopia. BMC Public Health 2012; 12(125): $1-10$

22. Yigzaw T, Yibric A and Kebede Y. Domestic violence around Gondar in northwest Ethiopia. Ethiopian Journal of Health Development. 2004; 18(3):133-9.

23. Heise LL. Violence against women: An integrated, ecological framework. Violence Against Women 1998; 4(3):262-290.

24. Dahlgren L, Emmelin M and Winkvist A: Qualitative methodology for international public health. 2nd edition. Umeå University Press; 2007.

25. World Health Organization (WHO). World Health Organization. Putting women first: ethical and safety recommendations for research on domestic violence against women. Geneva Switzerland, 2001; 18-30

26. Wirtz AL, Pham K, Glass N, Loochkartt S, Kidane T, Cuspoca D, Rubenstein LS, Singh $\mathrm{S}$ and $\mathrm{Vu} \mathrm{A}$. Gender-based violence in conflict and displacement: qualitative findings from displaced women in Colombia. Conflict and health. 2014; 8(1):10.

27. The Revised Family Code. Federal Negarit Gazetta of the Federal Democratic Republic of Ethiopia Extraordinary issue No. 1/2000. The Revised Family Code Proclamation No. 213/2000;16-17

28. Yigzaw T, Berhane Y, Deyessa N, Kaba M. Perceptions and attitude towards violence against women by their spouses: A qualitative study in Northwest Ethiopia. Ethiopian Journal of Health Development. 2010; 24(1):39-45.

29. Bair-Merritt MH, Shea Crowne S, Thompson DA, Sibinga E, Trent $\mathrm{M}$ and Campbell J. Why do women use intimate partner violence? A systematic review of women's motivations. Trauma, Violence, \& Abuse. 2010; 11(4):178-189.

30. Swain SN, Saggurti N, Battala M, Verma RK and Jain AK. Experience of violence and adverse reproductive health outcomes, HIV risks among mobile female sex workers in India. BMC public health. 2011; 11(1):357.

31. Heise L and Garcia-Moreno C. Violence by intimate partners. World Report on Violence and Health. Geneva: World Health Organization. 2002: 87-121.

32. O'Farrel TJ, Fals-Stewart W, Murphy M and Murphy CM. Partner violence before and after individually based alcoholism treatment for male alcoholic patients. $J$. Consult Clin Psycho 2003; 71: 92-102.. 